\title{
Having Private Cancer Insurance in Korea: Gender Differences
}

\author{
Ki-Bong Yoo ${ }^{1 \&}$, Jin-Won Noh ${ }^{1 \&}$, Young Dae Kwon ${ }^{2}$, Kyoung Hee Cho ${ }^{3}$, Young \\ Choi $^{3}$, Jae-Hyun Kim ${ }^{3 *}$
}

\begin{abstract}
Background: As coverage of public insurance is not sufficient to cover diagnosis or treatment of cancer, having private health insurance is important to prepare for unexpected expenses of cancer. The purpose of this study was to assess factors associated with having private cancer insurance, considering gender among the sociodemographic factors and health behavior. Materials and Methods: We used data from the 2011 Korea Health Panel, which included 10,871 participants aged 20 years and older. Socio-demographics, health behavior, and perceived cancer risk were the independent variables and having private cancer insurance was the dependent variable. Multivariable logistic regression analysis was used to identify factors associated with having private cancer insurance. Results: The variables relating to middle age, higher education, higher household income, married men, and the perceived cancer risk groups of 1-10\% and 11-30\% were significantly associated with having private cancer insurance. Additionally, females who had private non-cancer health insurance were positively associated with the dependent variables $(\mathrm{OR}=1.36$; 95\% $\mathrm{CI}=1.17-1.57)$. Education, smoking status, exercise, and perceived cancer risk possibility were significantly associated with having private cancer insurance only among women. The men lowered the overall percentages of those having private cancer insurance $(O R=0.53$, $95 \% \mathrm{CI}=0.45-0.63)$. Conclusions: We found that there were significant differences between men and women who had private cancer insurance. Women with private cancer insurance are more likely to follow precautionary health behavior than men. This could be interpreted as resulting from masculine ideologies. It is important to make males recognize the seriousness of the cancer risk. In general, household income was highly associated with private cancer insurance. These results reveal an inequity among the buyers of private cancer insurance in terms of economic status level, education level, and health condition.
\end{abstract}

Keywords: Private cancer insurance - perceived cancer risk - gender differences - Korea

Asian Pac J Cancer Prev, 16 (17), 7981-7986

\section{Introduction}

Cancer is a leading cause of death around world. The incidence rate of cancer is increasing based on the demographics of an aging population, and risk factors such as health behaviors associated with urbanization and economic development (Torre et al., 2015). In Korea, $28.8 \%$ of the deaths in 2013 were caused by cancer (Statistics Korea, 2014). It was the highest death rate ever in Korea. This rate increased by $14.4 \%$ over the period 2003 to 2012 . Additionally, during 2000 to 2010 , the economic burden of cancer increased from $\$ 11,424$ to $\$ 20,858$, with an average annual growth rate of $8.9 \%$ (Lee et al., 2015). As a result, the Korean government has expanded health insurance coverage for cancer including decreasing out-of-pocket payments (Lee and Shaw, 2014; Kim and Kwon, 2015). The out-of-pocket expenditure on cancer has dropped around $30 \%$ and this number has been maintained from 2007 to 2010 (You et al., 2013).
The Korean public health expenditure was $55.5 \%$ of its health expenditure in 2014, whereas the country average of those in the Organization for Economic Co-operation and Development (OECD) was $72.6 \%$ in 2013 (Organization for Economic Co-operation and Development, 2015). Although the Korean expenditure was lower than the average, cancer medical expenditure, however, is still very expensive for most individuals; it is a huge financial burden for patients. A previous research report stated that in $2012,62.7 \%$ of patients spent over six million won (approximately 5,235 USD) for cancer treatment, and 19.6\% spent over 20 million won (approximately 17,448 USD) (Kim et al., 2012).

National health insurance in Korea offers universal health coverage. However, many people purchase private health insurance because of the low coverage of the national health insurance. Private health insurance in Korea is supplemental health coverage. The rate of individuals with private health insurance in Korea was 
Ki-Bong Yoo et al

$78 \%$ in 2009 and this percentage has been increasing (Cho, 2013). There are several studies that identify factors associated with having private health insurance; the main associated factors are income, education level, and age (Lim et al., 2007; Yoo et al., 2012).

However, there has not yet been a study around private cancer insurance that includes cancer diagnosis or cancer treatment. In identifying the factors associated with private cancer health insurance, we took note of gender differences. In general, women experience poorer health conditions than men (Denton et al., 2004), and as a result, they visit and/or seek out health professionals more than men (Galdas et al., 2005). Specifically, faced with the potential of breast and cervical cancer, women considered cancer prevention more than men. Moreover, women are more likely to have private cancer insurance than men. However, in Korea, women's income, the main factor associated with having private health insurance, is not higher than men. The labor force participation rate of women ages 15 to 64 in Korea was $54.5 \%$ in 2010

Table 1. General Characteristics of Study Variables at 2011

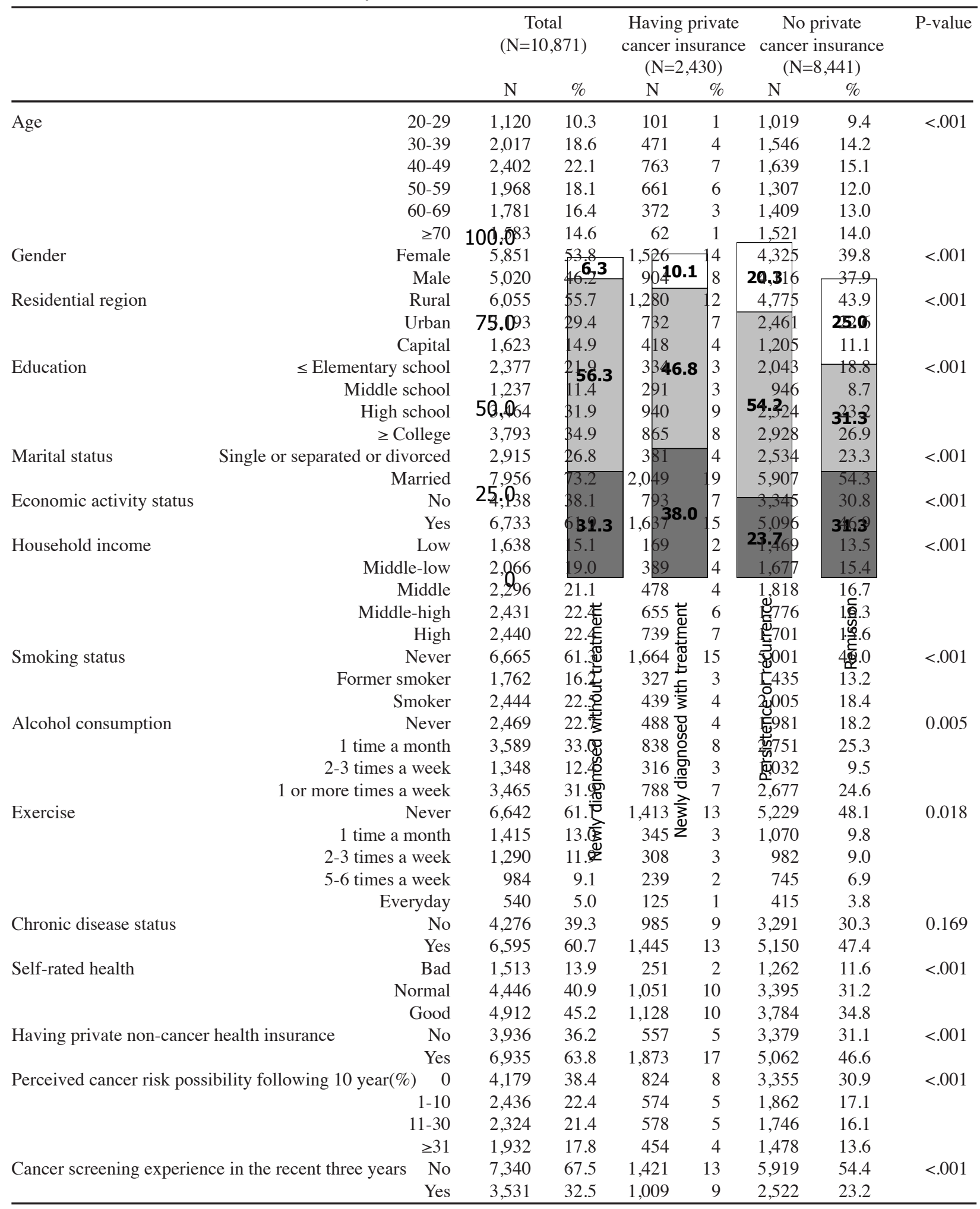


(OECD, 2012). Therefore, in this study, those having private cancer insurance will be assessed while looking at gender differences, considering income, and perceived risk of cancer. The objective of this study is to investigate the factors associated with having private cancer insurance.

\section{Materials and Methods}

\section{Study population}

We used 2011 Korea Health Panel data from the Korea Institute for Health and Social Affairs (KIHSA) and the National Health Insurance Service (NHIS). The Korea Health Panel selected samples with a method of 2-stage cluster and researched all members of the selected households to secure representation. The data provides healthcare utilization, expenditure on health, demographics, and health behaviors of families and individuals. Its strength is that it is a nationally representative sample. Since the variable, perception of cancer risk, was only included in the 2011 data, we used just 2011 data. The individuals included numbered 17,037 in the 2011 baseline data. A total of 10,871 subjects were used after excluding for those aged under $20(\mathrm{~N}=4,089)$, subjects with cancer $(\mathrm{N}=657)$, as well as missing data $(\mathrm{N}=1,422)$.

The Korea Health Panel was approved by the National Statistical Office and all individual data was guaranteed anonymity. The raw data are an open source and anyone who wants to use the data can acquire the data set from the Korea Health Panel website (www.khp.re.kr) through an application procedure.

\section{Dependent variable}

Having private cancer insurance was the dependent variable. It was captured by the question that asked, "What kind of private health insurance do you have?" Responses were categorized as "General sickness insurance," "Cancer insurance," "Accident insurance,", "Long-term care insurance," "Annuity or whole life insurance," or "Others."

\section{Independent variables}

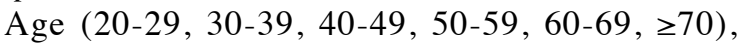
residential region (rural, urban, metropolitan), education (elementary school or lower, middle school, high school, college or higher), marital status (single, separated, divorced, or married), economic activity status (yes or no), and household income were included as sociodemographic variables. Household income was calculated by dividing the household monthly income by the square root of the household size (Deaton and Lubotsky, 2003).

As health behavior variables, smoking status (never, former smoker, or smoker), alcohol consumption (never, one time a month, two-three times a week, or one or more times a week), and exercise (never, one time a month, two-three times a week, or five-six times a week) were included.

Chronic disease status (yes or no), self-rated health (bad, normal, or good), having private non-cancer health insurance (yes or no), and the percentage of the perceived cancer risk possibility in the next 10 years $(0 \%, 1-10 \%$,

\section{having Private Cancer Insurance}

\begin{tabular}{|c|c|c|}
\hline & OR & $95 \% \mathrm{CI}$ \\
\hline \multicolumn{3}{|l|}{ Age } \\
\hline $20-29$ & 1.00 & \\
\hline $30-39$ & 2.70 & $(2.10-3.48)$ \\
\hline $40-49$ & 4.05 & $(3.12-5.25)$ \\
\hline $50-59$ & 4.70 & $(3.57-6.19)$ \\
\hline $60-69$ & 3.14 & $(2.33-4.22)$ \\
\hline$\geq 70$ & 0.69 & $(0.47-1.01)$ \\
\hline \multicolumn{3}{|l|}{ Gender } \\
\hline Female & 1.00 & \\
\hline Male & 0.54 & $(0.46-0.64)$ \\
\hline \multicolumn{3}{|l|}{ Residential region } \\
\hline Rural & 1.00 & \\
\hline Urban & 1.05 & $(0.94-1.17)$ \\
\hline Capital & 1.17 & $(1.02-1.34)$ \\
\hline \multicolumn{3}{|l|}{ Education } \\
\hline$\leq$ Elementary school & 1.00 & \\
\hline Middle school & 1.13 & $(0.93-1.37)$ \\
\hline High school & 1.28 & $(1.07-1.53)$ \\
\hline$\geq$ College & 1.24 & $(1.02-1.51)$ \\
\hline \multicolumn{3}{|l|}{ Marital status } \\
\hline \multicolumn{2}{|c|}{ Single or separated or divorced } & 1.00 \\
\hline Married & 1.25 & $(1.08-1.44)$ \\
\hline \multicolumn{3}{|l|}{ Economic activity status } \\
\hline No & 1.00 & \\
\hline Yes & 1.02 & $(0.91-1.15)$ \\
\hline \multicolumn{3}{|l|}{ Household income } \\
\hline Low & 1.00 & \\
\hline Middle-low & 1.31 & $(1.07-1.62)$ \\
\hline Middle & 1.27 & $(1.03-1.56)$ \\
\hline Middle-high & 1.67 & $(1.36-2.06)$ \\
\hline High & 1.86 & $(1.50-2.3)$ \\
\hline \multicolumn{3}{|l|}{ Smoking status } \\
\hline Never & 1.00 & \\
\hline Former smoker & 0.95 & $(0.79-1.15)$ \\
\hline Smoker & 0.88 & $(0.74-1.06)$ \\
\hline \multicolumn{3}{|l|}{ Alcohol consumption } \\
\hline Never & 1.00 & \\
\hline 1 time a month & 1.08 & $(0.94-1.24)$ \\
\hline 2-3 times a week & 1.12 & $(0.94-1.34)$ \\
\hline 1 or more times a week & 1.15 & $(0.98-1.34)$ \\
\hline \multicolumn{3}{|l|}{ Exercise } \\
\hline Never & 1.00 & \\
\hline 1 time a month & 1.03 & $(0.89-1.19)$ \\
\hline 2-3 times a week & 1.02 & $(0.88-1.18)$ \\
\hline 5-6 times a week & 1.03 & $(0.87-1.22)$ \\
\hline Everyday & 1.15 & $(0.92-1.44)$ \\
\hline \multicolumn{3}{|l|}{ Chronic disease status } \\
\hline No & 1.00 & \\
\hline Yes & 1.02 & $(0.91-1.14)$ \\
\hline Self-rated health & Bad & 1.00 \\
\hline Normal & 1.18 & $(0.99-1.39)$ \\
\hline Good & 1.14 & $(0.97-1.36)$ \\
\hline \multicolumn{3}{|c|}{ Having private non-cancer health insurance } \\
\hline No & 1.00 & \\
\hline Yes & 1.34 & $(1.19-1.51)$ \\
\hline \multicolumn{3}{|c|}{ Perceived cancer risk possibility following 10 year(\%) } \\
\hline 0 & 1.00 & \\
\hline $1-10$ & 1.13 & $(0.99-1.29)$ \\
\hline $11-30$ & 1.19 & $(1.04-1.35)$ \\
\hline$\geq 31$ & 1.08 & $(0.94-1.25)$ \\
\hline \multicolumn{3}{|c|}{ Cancer screening experience in the recent three years } \\
\hline No & 1.00 & \\
\hline Yes & 1.24 & $(1.12-1.38)$ \\
\hline
\end{tabular}




\section{Ki-Bong Yoo et al}

$11-30 \%, 31 \%$ or greater) were also included in the study. In terms of having private non-cancer health insurance: if subjects answered no, they did not have any private health insurance. If they answered yes, subjects had one or more private non-cancer health insurance. Non-cancer health insurance indicated all private health insurance except private cancer insurance. The perceived risk of cancer in the next 10 years was captured by the question "How do you assess your cancer risk over the next 10 years?" The answer to this was a continuous percentage divided into $0 \%, 1-10 \%, 11-30 \%$, or $31 \%$ or greater.

\section{Statistical analysis}

The distribution of the general characteristics was analyzed by the chi-square test. Multiple logistic regression was used to identify the factors associated with having private cancer insurance. All the independent variables were adjusted in the regression model. The significance level was 0.05 . All statistical analyses were conducted using SAS 9.3 (SAS Institute Inc., Cary, NC, USA).

\section{Results}

Table 1 lists the general characteristics in the study. The total sample size was 10,871 . Of this, $2,430(22.4 \%)$

Table 3. Subgroup Analysis for Having Private Cancer Insurance by Gender

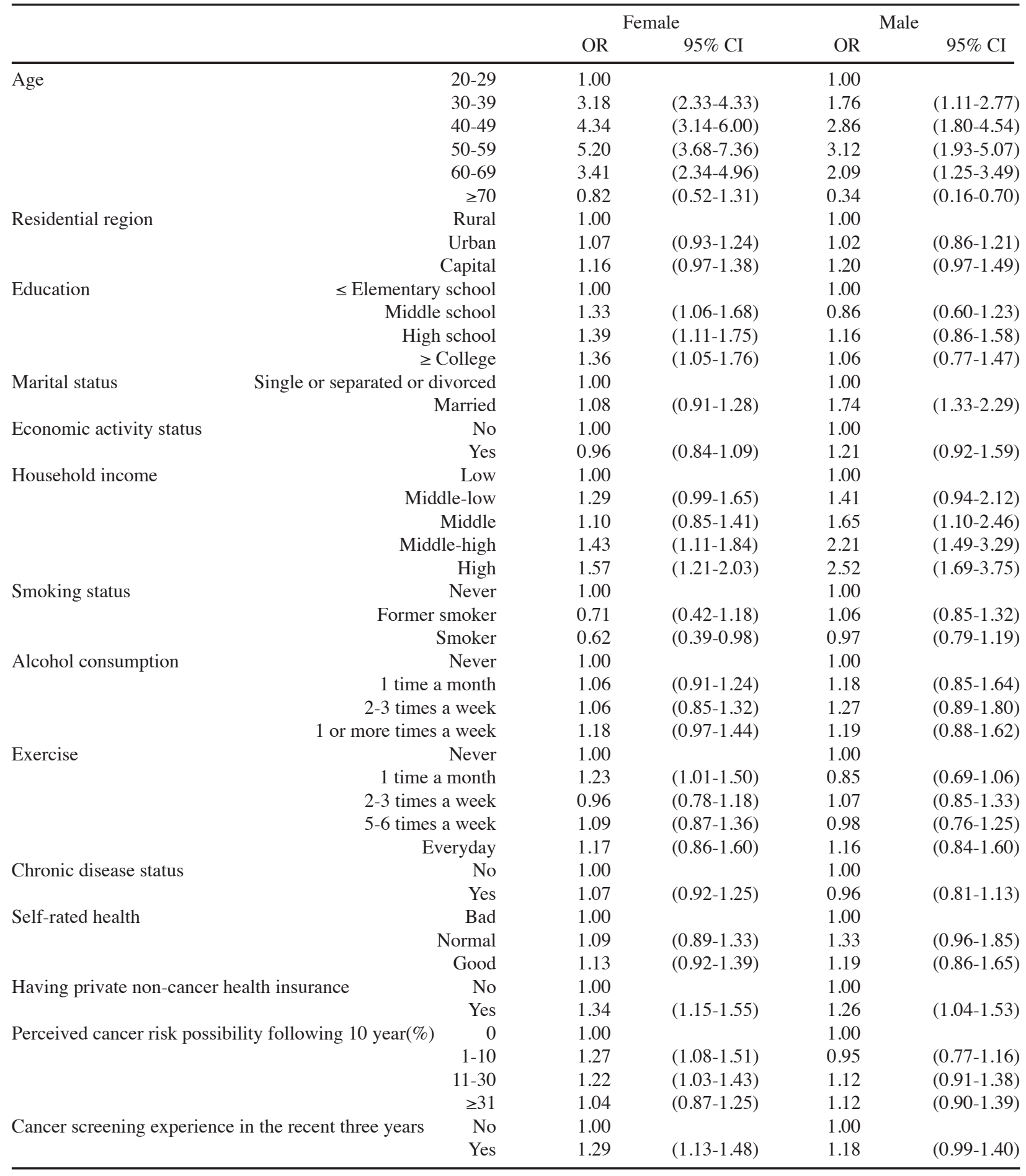


subjects had private cancer insurance and 8,441(77.6\%) did not. All the independent variables, except for chronic disease status, were significantly related to having private cancer insurance.

Table 2 shows the results of the multiple logistic regression. We found that women were likely to have private cancer insurance more than men $(\mathrm{OR}=0.54,95 \%$ $\mathrm{CI}=0.46-0.64)$, meaning; and, participants who were middle aged were more likely to have private cancer insurance. Higher education and higher household income were significantly related with having private cancer insurance. Health behavior, such as smoking status, alcohol consumption, exercise, chronic disease status, and selfrated health were not significantly related. Subjects who had private non-cancer health insurance were positively associated with also having private cancer insurance $(\mathrm{OR}=1.34 ; 95 \% \mathrm{CI}=1.19-1.51)$. Perceived cancer risk was partly significantly associated with having private cancer insurance. Compared to those who answered that their perceived cancer risk was $0 \%$, those who answered that their perceived cancer risk was $1-10 \%$ or $11-30 \%$, were more likely to have private cancer insurance.

Table 3 shows the results of the subgroup analysis by gender. Education, smoking status, exercise, cancer screening experience, and perceived cancer risk possibility were significantly associated with having private cancer insurance only among women (i.e., not men). On the other hand, marital status was significantly associated with having private cancer insurance $(\mathrm{OR}=1.74 ; 95 \%$ $\mathrm{CI}=1.33-2.29$ ) only among men. As for the association of household income, having private non-cancer health insurance, and age with having private cancer insurance, these were almost same for both men and women.

\section{Discussion}

In this study, we identified the factors associated with having private cancer insurance. Age, household income, marital status, having private non-cancer health insurance, and perceived cancer risk were identified as factors associated with having private cancer insurance.

Remarkable results were derived from the subgroup results by gender. Although perceived cancer risk is related to the likelihood of better health behaviors (Rogers and Mewborn, 1976), it was statistically significant in relation to private cancer insurance among only women. The perceived cancer risk is a strong motivation for precautionary health behavior (Abotchie and Shokar, 2009; Cullati et al., 2009). It was associated with participating in cancer screening (Goldman and Risica, 2004; Kim et al., 2014), and risk-reducing activities (Katapodi et al., 2004). As a previous study indicated (Kim et al., 2014), precautionary health behavior, such as cancer screening, appears to be associated with increased likelihood of perceiving cancer risk, resulting in an inverted U-shaped relationship between extremely low or extremely high perceived cancer risk.

The results from the women show that women prepare for cancer. Women generally considered the risks of cervical cancer and/or breast cancer (Kash et al., 1995), and made use of medical services more than men (Ladwig
Having Private Cancer Insurance in Korea: Gender Differences et al., 2000). In addition, preventive care utilization, such as medical check-ups, was higher among women than men (Vaidya et al., 2012). Previous studies reported that reasons for women's high medical utilization included being responsible for managing their family's health and having the female hormone estrogen (Oksuzyan et al., 2008).

In addition, although statistically significant in only women, health behavior factors, such as smoking status and exercise, were also associated with having private cancer insurance.

In contrast, a previous study reported that men's low medical utilization was due to socialization of masculine ideologies, and men were more likely to seek help after disease onset (Galdas et al., 2005). Even men that are highly educated and perceive their cancer risk as high did not purchase private cancer insurance according to this study.

Overall, a high perceived cancer risk was not significant in any group. This may relate to the fact that Korean private health insurance companies use underwriters when someone purchases private health insurance. Although chronic disease status and self-rated health were not associated with having private cancer insurance, having private non-cancer health insurance, which was able to represent the subject's health condition, was significantly associated with these. A poor health condition was negatively associated with having private health insurance (Huh and Kim, 2009; Kiil, 2012; Yoo et al., 2012). This implies that there is risk selection in the Korean insurance industry (Shin, 2012). Household income was highly associated with having private cancer insurance. The high-income group can purchase private cancer insurance, and thereby reduce the financial burden of healthcare expenditures. However, the low-income group cannot. These results indicate that there is an inequity among the buyers of private cancer insurance in terms of economic status level, education level, and health condition.

A previous study (Weyh et al., 2015) showed that uninsured patients, without cancer insurance, had a greater tendency for prolonged hospital stays. This could reflect their general lack of preventive care, increased use of tobacco and alcohol, along with more advanced disease, and delays in initiating treatment. Therefore, policy makers should be aware of the importance of administering primary cancer prevention to uninsured individuals without cancer insurance.

There are strengths and limitations to this study. The strength of this study is that the data are representative of the general population. Therefore, the results can be generalized to the Korean population as a whole. A limitation of the study is that its design is as a crosssectional study. The results are not causal effects. Second, there are many types of private cancer insurance, but we were not able to distinguish these and thus just focused on whether or not the subject was insured. Third, we could not fully exclude the effects of information bias as the measurement of all variables included in this study was based on a self-reported questionnaire survey using open source data from KHPS 2009 to 2011. 
For further study, researchers should conduct analysis using detailed private cancer insurance data and longitudinal data. Additionally, the effects of private health insurance on healthcare utilization and expenditures should be identified. These are still in debate in Korea (Kang et al., 2005; Lee et al., 2010; Shin, 2012; Jeon and Kwon, 2013). Policy makers should consider gender differences and the inequity in private health insurance and private cancer insurance. It is important to make male to recognize the seriousness of the cancer risk. The inequity in healthcare utilization is still a problem in Korea (Lee et al., 2015; Park, 2015). Finally, as cancer insurance coverage and health policy continue to change over time, it is necessary to consider the environment of health policy and economic circumstances.

\section{Acknowledgements}

This study was approved by the Institutional Review Board of the Catholic University (MC 15EISI0002).

\section{References}

Abotchie PN, Shokar NK (2009). Cervical cancer screening among college students in ghana: knowledge and health beliefs. Int J Gynecol Cancer, 19, 412-6.

Cho HJ (2013). Equity in health care: current situation in South Korea. J Korean Med Assoc, 56, 184-94.

Cullati S, Charvet-Berard AI, Perneger TV (2009). Cancer screening in a middle-aged general population: factors associated with practices and attitudes. BMC Public Health, 9, 118 .

Deaton A, Lubotsky D (2003). Mortality, inequality and race in American cities and states. Soc Sci Med, 56, 1139-53.

Denton M, Prus S, Walters V (2004). Gender differences in health: a Canadian study of the psychosocial, structural and behavioural determinants of health. Soc Sci Med, 58, 2585-600

Galdas PM, Cheater F, Marshall P (2005). Men and health helpseeking behaviour: literature review. J Adv Nurs, 49, 616-23.

Goldman RE, Risica PM (2004). Perceptions of breast and cervical cancer risk and screening among Dominicans and Puerto Ricans in Rhode Island. Ethn Dis, 14, 32-42.

Huh E, Kim JK (2009). Middle-aged and old people's purchase and expenditure decision factors of private health insurance. Journal of Consumer Studies, 20, 107-27.

Jeon B, Kwon S (2013). Effect of private health insurance on health care utilization in a universal public insurance system: a case of South Korea. Health Policy, 113, 69-76.

Kang SW, Kwon WD, C.H. Y (2005). Effects of supplemental insurance on health care utilization and expenditures among cancer patients in Korea. Korean J of Health Policy \& Administration, 15, 65-80.

Kash KM, Holland JC, Osborne MP, et al (1995). Psychological counseling strategies for women at risk of breast cancer. $J$ Natl Cancer Inst Monogr, 73-9.

Kiil A (2012). What characterises the privately insured in universal health care systems? A review of the empirical evidence. Health Policy, 106, 60-75.

Kim H, Jang J, Sohn HS (2012). Anticancer drug use and out-of-pocket money burden in korean cancer patients: a questionnaire study. Kor J Clin Pharm, 22, 239-50.

Kim JH, Park EC, Yoo KB (2014). Impact of perceived cancer risk on the cancer screening rate in the general korean population: results from the korean health panel survey data.
Asian Pac J Cancer Prev, 15, 10525-9.

Kim S, Kwon S (2015). Impact of the policy of expanding benefit coverage for cancer patients on catastrophic health expenditure across different income groups in South Korea. Social Science \& Medicine, 138, 241-7.

Ladwig KH, Marten-Mittag B, Formanek B, et al (2000). Gender differences of symptom reporting and medical health care utilization in the German population. Eur J Epidemiol, 16, 511-8.

Lee KS, Chang HS, Lee SM, et al (2015). Economic Burden of Cancer in Korea during 2000-2010. Cancer Res Treat, 47, 387-98.

Lee W-Y, Shaw I (2014). The impact of out-of-pocket payments on health care inequity: the case of national health insurance in South Korea. International Journal of Environmental Research and Public Health, 11, 7304-18.

Lee YC, Im BH, Park YH (2010). The determinants and comparison of health behavior and health service by private medical insurance on national health-nutrition survey. The Journal of the Korea Contents Association, 10, 190-204.

Lim JH, Kim SG, Lee EM, et al (2007). The determinants of purchasing private health insurance in Korean cancer patients. J Prev Med Public Health, 40, 150-4.

OECD 2012. OECD Employment Database, Paris, Organization for economic cooperation and development.

Oksuzyan A, Juel K, Vaupel JW, et al (2008). Men: good health and high mortality. Sex differences in health and aging. Aging Clin Exp Res, 20, 91-102.

Organization for Economic Co-operation and Development 2015. OECD health data, organization for economic cooperation and development.

Park JM (2015). Equity of access under Korean universal health insurance. Asia Pac J Public Health, 27, 914-24.

Rogers RW, Mewborn CR (1976). Fear appeals and attitude change: effects of a threat's noxiousness, probability of occurrence, and the efficacy of coping responses. J Pers Soc Psychol, 34, 54-61.

Shin J (2012). Private health insurance in South Korea: an international comparison. Health Policy, 108, 76-85.

Statistics Korea 2014. Annual report on the cause of death statistics 2013 Statistics Korea.

Torre LA, Bray F, Siegel RL, et al (2015). Global cancer statistics, 2012. CA Cancer J Clin, 65, 87-108.

Vaidya V, Partha G, Karmakar M (2012). Gender differences in utilization of preventive care services in the United States. $J$ Womens Health (Larchmt), 21, 140-5.

Weyh AM, Lunday L, McClure S (2015). Insurance status, an important predictor of oral cancer surgery outcomes. J Oral Maxillofac Surg.

Yoo KB, Cho WH, Lee M, et al (2012). The determinants of purchasing private health insurance among middle-aged and elderly Korean adults. Korean Journal of Hospital Management, 17, 23-36.

You CH, Kang S, Kwon YD, et al (2013). Time trend of outof-pocket expenditure among cancer inpatients: Evidence from Korean tertiary hospitals. Asian Pac J Cancer Prev, 14, 6985-9. 